\title{
Mejoramiento genético de avena en México
}

Héctor Eduardo Villaseñor-Mir

Julio Huerta-Espino

María Florencia Rodríguez-García ${ }^{\S}$

René Hortelano Santa-Rosa

Eduardo Espitia-Rangel

Eliel Martínez-Cruz

Campo Experimental Valle de México-INIFAP. Carretera Los Reyes-Texcoco km 13.5, Coatlinchán, Texcoco, Estado de México, México. CP. 56250. (villasenor.hector@inifap.gob.mx; huerta.julio@inifap.gob.mx; rodriguez.maria@inifap.gob.mx; hortelano.rene@inifap.gob.mx; espitia.eduardo@inifap.gob.mx; martinez.eliel@inifap.gob.mx).

${ }^{\S}$ Autora para correspondencia: rodriguez.maria@inifap.gob.mx.

\section{Resumen}

Con la creación del Instituto Nacional de Investigaciones Agrícolas (INIA), se inicia el mejoramiento genético de avena en México en el ahora Campo Experimental Valle de México (CEVAMEX). Inició con la introducción de germoplasma de EUA y Canadá, en 1962 se realizaron las primeras cruzas y en 1967 se liberan las variedades (Chihuahua y Cuauhtémoc). En los años 60 's a 80's se implementó la rotación de segregantes en diversos ambientes, obtener dos ciclos de selección al año, el método de selección masal gravimétrico y establecimiento de ensayos de rendimiento en ambientes contrastados. Actualmente el Instituto Nacional de Investigaciones Agrícolas y Pecuarias (INIFAP-CEVAMEX) cumple 61 años y ha liberado 33 variedades (18 como INIFAP). Durante 1985 al 2019 se ha incrementado el área sembrada de avena de aproximadamente 400000 a 900000 ha, debido a la productividad de las variedades actuales, destacando recientemente 'Turquesa' que ha superado en temporal las $8 \mathrm{t} \mathrm{ha}^{-1}$ de grano y que en los últimos 12 años se ha sembrado en 540000 ha, lo cual arrojó un beneficio de \$1 350 millones. Los retos a corto, mediano y largo plazo son incrementar la producción en temporales, fortalecer investigaciones en control genético de la roya del tallo, tolerancia a sequía y calidad nutricional del grano; y sembrar variedades con alto valor nutricional para consumo humano.

Palabras claves: Avena sativa L., fitomejoramiento, variedades.

Recibido: marzo de 2021

Aceptado: mayo de 2021 
El mejoramiento genético de avena (Avena sativa L.) en México inicio en 1960 con la creación del Instituto Nacional de Investigaciones Agrícolas (INIA) y a partir de 1985 conocido como Instituto Nacional de Investigaciones Forestales, Agrícolas y Pecuarias (INIFAP) y donde se establece el Campo Agrícola Experimental Valle de México (CEVAMEX).

El programa de mejoramiento inicia, bajo el mando del Ingeniero Rodolfo Moreno Gálvez, con la finalidad de obtener variedades resistentes a la roya del tallo (Puccinia graminis $\mathrm{f}$ sp. avena Erikss \& Henning) y el acame e incrementar el rendimiento unitario. A inicios de los 60's la superficie sembrada de avena fue de 80000 ha y el rendimiento promedio de grano de $800 \mathrm{~kg}$ ha $^{-1}$ (Jiménez, 1978).

El inicio del mejoramiento fue con la introducción de germoplasma de EUA y Canadá, que fue evaluado en diversos ambientes de temporal, lo que permitió seleccionar genotipos tolerantes a roya del tallo, con buen comportamiento bajo sequía y con mayor rendimiento, estas selecciones se utilizaron como progenitores en 1962 y fue así como se realizó el primer plan de cruzas en México, actividad, que ha sido importante y a la fecha es la fortaleza del CEVAMEX, dentro del INIFAP.

Entre las cruzas que se realizaron, se recombinó AB-177 x Putnam, sus generaciones segregantes $\mathrm{F}_{1}$ a $\mathrm{F}_{6}$ se evaluaron en primavera-verano (P-V) (Chapingo, Méx.) y otoño-invierno (O-I) (Roque, Gto.) y en 1967 da origen a las variedades Chihuahua y Cuauhtémoc, que en siembras de temporal sobresalieron por su rendimiento, tolerancia al acame y resistencia a roya del tallo, ventajas que permitieron impulsar la producción nacional (Jiménez, 1992).

Históricamente las siembras de avena se han visto afectadas por la roya del tallo, enfermedad agresiva, devastadora y con amplia diversidad de razas fisiológicas (Villaseñor et al., 2009), que cuando incide en variedades susceptibles causa pérdidas en el rendimiento de grano hasta $75 \%$ (Leyva et al., 2004). Durante la década de 1970 se liberaron ocho variedades que superaron a las ya sembradas, destacando Diamante R-31 (inmune a roya del tallo), Páramo (muy precoz y tolerante a la sequía) y Dorada (primera variedad con grano desnudo y precoz), variedades que permitieron que el programa recibiera reconocimiento a nivel internacional, por el mérito de recombinar germoplasma no adaptado y aprovechar genes de efectos aditivos para fijar caracteres deseables, como porte bajo, resistencia a la roya del tallo y grano desnudo, y por el esquema de selección masal o masivo implementado en las generaciones segregantes alternando ciclos de O-I en riego normal o limitado, con ciclos de P-V en temporales contrastantes (Villaseñor et al., 2009).

\section{Estrategias de mejoramiento en 35 años de investigación en el INIFAP}

A fines de la década de 1980 CEVAMEX consolida diversas técnicas de mejoramiento como son: 1) la introducción y recombinación donde utiliza como progenitores líneas generadas por el programa y las recombina con germoplasma introducido; 2) la hibridación para obtener cruzas simples y triples, y en casos específicos retrocruzas; 3) la rotación de segregantes en O-I y P-V en ambientes contrastantes; 4) la selección masal por el método gravimétrico, a través del flotado de semilla; 5) en P-V evaluar el segregante en localidades idóneas para la incidencia severa de roya del tallo; y 6) evaluación de ensayos de rendimiento en años y localidades en condiciones de temporal. 
A mediados de los 90's se registraron incrementos en la superficie de avena a nivel nacional, en 1996 se sembraron 460000 ha y $85 \%$ se destinó para forraje, de tal manera que a fines de la misma década se trabajó en el aumento en la producción de forraje y mayor producción de grano (Espitia et al., 2002). En 2002 se retoma el ensayo uniforme de avena (EUAVENA), que se evaluó hasta en 30 ambientes de temporal de Oaxaca hasta Chihuahua. En 2003 y 2005 se liberaron Obsidiana y Turquesa, que se caracterizaron por su alto rendimiento de grano, llegando a producir hasta $8 \mathrm{t}$ $\mathrm{ha}^{-1}$ y con una relación paja:grano de 58:42.

La roya del tallo ha sido el principal problema fitopatológico en el mejoramiento de avena, ya que el hongo muestra diversidad patogénica en México, por ejemplo, Mariscal et al. (2009) reporta que, en muestras colectadas en siembras comerciales de avena en México, identificó 24 razas fisiológicas. Gracias al mejoramiento genético, actualmente se dispone de líneas avanzadas con resistencia a diversas razas, debido a la acumulación de genes. Por otra parte, se está haciendo selección asistida por marcadores moleculares (SAM) que es la identificación de marcadores ligados a los genes de resistencia a la roya del tallo (Torres-Pacheco et al., 2007).

En 2021 el programa de mejoramiento genético de avena cumple 61 años, con 122 generaciones de recombinación y selección y ha liberado 33 variedades, 18 de ellas como INIFAP. De 1985 al 2019, el tiempo que lleva el INIFAP a raíz de su creación, se ha incrementado el área sembrada de avena aproximadamente 400000 a 900000 ha, gracias a la productividad de las variedades, dentro de las que destaca Turquesa, que en los últimos 12 años se ha sembrado en 540000 ha arrojado un beneficio de \$1 350 millones. En síntesis, prácticamente 100\% de la producción de avena en México durante las últimas cinco décadas se ha logrado con las contribuciones del programa de mejoramiento genético del INIFAP, que puede ubicarse entre los más exitosos del instituto. En el Cuadro 1 se enlistan las variedades de avena y el año de liberación por el INIFAP.

Cuadro 1. Variedades de avena (Avena sativa) liberadas por el INIFAP de 1967 a la fecha.

\begin{tabular}{lccc}
\hline \multicolumn{1}{c}{ Variedad } & Año de liberación & Resistencia a roya del tallo & Usos \\
\hline Cuauhtémoc & 1967 & $\mathrm{~S}$ & Grano-forraje \\
Chihuahua & 1967 & $\mathrm{~S}$ & Grano-forraje \\
Guelatao & 1972 & $\mathrm{~S}$ & Grano-forraje \\
Páramo & 1974 & $\mathrm{~S}$ & Grano-forraje \\
Diamante R-31 & 1974 & $\mathrm{MR}$ & Grano-forraje \\
Huamantla & 1974 & $\mathrm{~S}$ & Grano-forraje \\
Tarahumara & 1974 & $\mathrm{~S}$ & Grano-forraje \\
Gema & 1978 & $\mathrm{~S}$ & Grano-forraje \\
Tulancingo & 1979 & $\mathrm{~S}$ & Grano-forraje \\
Juchitepec & 1987 & $\mathrm{MS}-\mathrm{R}$ & Grano-forraje \\
Dorada & 1987 & $\mathrm{MS}-\mathrm{R}$ & Grano-forraje \\
Pampas & 1989 & $\mathrm{MS}-\mathrm{R}$ & Grano-forraje \\
Papigochi & 1989 & $\mathrm{MS}-\mathrm{R}$ & Grano-forraje \\
\hline
\end{tabular}




\begin{tabular}{lccc}
\hline \multicolumn{1}{c}{ Variedad } & Año de liberación & Resistencia a roya del tallo & Usos \\
\hline Babícora & 1989 & MS-R & Grano-forraje \\
Cusihuiriachi & 1989 & MS-R & Grano-forraje \\
Rarámuri & 1989 & S & Grano-forraje \\
Karma & 1998 & MS-R & Grano-forraje \\
Avemex & 1998 & S & Grano-forraje \\
Obsidiana & 2002 & MS & Grano-forraje \\
Menonita & 2002 & MS & Grano-forraje \\
Bachiniva & 2002 & MS & Grano-forraje \\
Teporaca & 2002 & MS-R & Grano-forraje \\
Turquesa & 2006 & MS & Grano-forraje \\
Arareco & 2007 & MS & Grano-forraje \\
Ágata & 2019 & MR-R & Grano-forraje \\
Jade & 2020 & MR-R & Grano-forraje \\
\hline
\end{tabular}

$\mathrm{R}=$ resistente $\mathrm{MR}=$ moderada resistencia $\mathrm{MS}=$ moderada susceptibilidad; $\mathrm{S}=$ susceptible a retos a corto, mediano $\mathrm{y}$ largo plazo.

El cultivo de avena en México en las dos últimas décadas se produce bajo temporal, en tierras de bajo potencial productivo, se considera un cultivo emergente cuando se siniestran o ya no es tiempo de sembrar otros cultivos y como un forraje estratégico en la reconversión productiva de las tierras de vocación agrícola a explotación pecuaria.

Entre sus bondades, se tiene: i) es un excelente forraje que se aprovecha desde etapas tempranas de crecimiento (encañe) hasta madurez y que es altamente demandado para la alimentación pecuaria; ii) requiere menos tiempo para producirse y menos insumos que otros cultivos; iii) es una planta rústica que expresa buen comportamiento desde temporales erráticos de baja precipitación (El Llano, Aguascalientes) hasta partes altas y lluviosas (Río Frío, Estado de México); y iv) es tolerante a ambientes de sequía.

El éxito de la producción de avena en México dependerá de las variedades generadas por el INIFAP, ya que mediante éstas se logrará controlar genéticamente la roya del tallo, incrementar la calidad y cantidad del forraje y lograr una producción estable y sustentable. El programa de mejoramiento debe de seguir trabajando de manera organizada y coordinada para lograr su continuidad en la generación de líneas y en la evaluación de los ensayos nacionales.

\section{Conclusiones}

Será importante incorporar jóvenes investigadores y contemplar los siguientes retos: a) a corto plazo, incrementar la producción en temporales lluviosos y fortalecer investigaciones en control genético de la roya del tallo, tolerancia a sequía y calidad nutricional del grano; b) a mediano plazo controlar la roya del tallo e incrementar el área en temporales medio lluviosos; y c) a largo plazo incrementar el área en ambientes de sequía y en riego en el noroeste y sembrar variedades que produzcan grano con alto valor nutricional para consumo humano. 


\section{Literatura citada}

Espitia, R. E.; Villaseñor, M. H. E.; Tovar, R.; Pérez, P. y Limón, A. 2002. Momento óptimo de corte y comparación de genotipos de avena forrajera. In: Memoria del XIX Congreso Nacional de Fitogenética. Saltillo, Coahuila, México. 282 p.

Jiménez, G. C. A. 1978. Avena. In: Cervantes, S. T. (Ed.). Recursos genéticos disponibles en México. Sociedad Mexicana de Fitogenética. Chapingo, Estado de México, México. 103-110 pp.

Jiménez, G. C. A. 1992. Descripción de variedades de avena cultivadas en México. SARH, INIFAP, CIRCE, CEVAMEX. Chapingo, Estado de México, México. Folleto técnico núm. $3.72 \mathrm{p}$.

Leyva, M. S. G.; Espitia, R. E.; Villaseñor, M. H. E. y Huerta-Espino, J. 2004. Pérdidas ocasionadas por Puccinia graminis f. sp. Avenae, causante de la roya del tallo en seis variedades de avena (Avena sativa L.) en los Valles Altos de México. Rev. Mex. Fitopatol. 22(2):166-171.

Mariscal, A. L. A.; Huerta, E. J.; Villaseñor, M. H. E.; Leyva, M. S. G.; Sandoval, I. J. S. y Benítez R. I. 2011. Selección de genotipos de avena para la identificación de razas de roya del tallo. Rev. Mex. Cienc. Agric. 2(4):593-600.

Torres, P. I.; González, C. M. M.; Villaseñor, M. H. E.; Huerta, E. J.; Villordo, P. E.; Espitia, R. E.; Guevara, G. G. y Guevara, O. L. 2007. Marcadores genéticos de resistencia a roya de tallo (Puccinia graminis f. sp. avenae) en avena (Avena sativa L. Agric. Téc. Méx. 33(3):221-230.

Villaseñor, M. H. E.; Huerta-Espino, J.; Rodríguez, G. M. F.; Hortelano, S. R. R.; Martínez, C. E. y Espitia, R. E. 2009. Programa nacional de mejoramiento genético de avena en México: Reseña histórica 66 años al servicio de México 1943-2009. Campo Experimental Valle de México. Publicación especial. 1(1):33-43. 